\title{
Upper-Ocean Response to Hurricane Frances (2004) Observed by Profiling EM-APEX Floats*
}

\author{
THOMAS B. SANFORD \\ Applied Physics Laboratory, and School of Oceanography, University of Washington, Seattle, Washington \\ JAMES F. PRICE \\ Woods Hole Oceanographic Institution, Woods Hole, Massachusetts \\ JAMES B. GIRTON \\ Applied Physics Laboratory, and School of Oceanography, University of Washington, Seattle, Washington
}

(Manuscript received 13 July 2009, in final form 12 November 2010)

\begin{abstract}
Three autonomous profiling Electromagnetic Autonomous Profiling Explorer (EM-APEX) floats were air deployed one day in advance of the passage of Hurricane Frances (2004) as part of the Coupled Boundary Layer Air-Sea Transfer (CBLAST)-High field experiment. The floats were deliberately deployed at locations on the hurricane track, $55 \mathrm{~km}$ to the right of the track, and $110 \mathrm{~km}$ to the right of the track. These floats provided profile measurements between 30 and $200 \mathrm{~m}$ of in situ temperature, salinity, and horizontal velocity every half hour during the hurricane passage and for several weeks afterward. Some aspects of the observed response were similar at the three locations-the dominance of near-inertial horizontal currents and the phase of these currents-whereas other aspects were different. The largest-amplitude inertial currents were observed at the $55-\mathrm{km}$ site, where SST cooled the most, by about $2.2^{\circ} \mathrm{C}$, as the surface mixed layer deepened by about $80 \mathrm{~m}$. Based on the time-depth evolution of the Richardson number and comparisons with a numerical ocean model, it is concluded that SST cooled primarily because of shear-induced vertical mixing that served to bring deeper, cooler water into the surface layer. Surface gravity waves, estimated from the observed high-frequency velocity, reached an estimated $12-\mathrm{m}$ significant wave height at the $55-\mathrm{km}$ site. Along the track, there was lesser amplitude inertial motion and SST cooling, only about $1.2^{\circ} \mathrm{C}$, though there was greater upwelling, about $25-\mathrm{m}$ amplitude, and inertial pumping, also about $25-\mathrm{m}$ amplitude. Previously reported numerical simulations of the upper-ocean response are in reasonable agreement with these EMAPEX observations provided that a high wind speed-saturated drag coefficient is used to estimate the wind stress. A direct inference of the drag coefficient $C_{D}$ is drawn from the momentum budget. For wind speeds of $32-47 \mathrm{~m} \mathrm{~s}^{-1}, C_{D} \sim 1.4 \times 10^{-3}$.
\end{abstract}

\section{Introduction}

Hurricanes are among the most destructive natural hazards. Timely, accurate predictions of hurricane path and strength can help reduce unnecessary losses, and there is a significant ongoing effort to improve all aspects of hurricane forecasting. One aspect of this is

\footnotetext{
* Supplemental information related to this paper is available at the Journals Online Web site: http://dx.doi.org/10.1175/2010JPO4313.s1.

Corresponding author address: T. B. Sanford, Applied Physics Laboratory, University of Washington, Seattle, WA 98105.

E-mail: sanford@apl.washington.edu
}

hurricane-ocean interaction. It is well known that hurricanes extract a significant fraction of their heat and water vapor energy supply from the local sea surface, with a somewhat larger fraction already present in the warm, moist tropical atmosphere. Historical oceanographic observations and satellite imagery show that an intense, slowly moving hurricane may cool the sea surface by $2^{\circ}-6^{\circ} \mathrm{C}$, which is comparable to the typical airsea temperature difference (Price 1981; Emanuel 1999; Zedler et al. 2002). Sea surface temperature (SST) cooling of as little as $1^{\circ} \mathrm{C}$ in the inner core of hurricanes has been shown to lead to as much as a $40 \%$ change in enthalpy flux from the sea (Cione and Uhlhorn 2003). The amplitude of the surface cooling and thus of hurricane-ocean interaction 
likely depends on several factors: wind stress and duration (i.e., storm's strength, size, and speed), the surface gravity wave field, and the initial temperature and density profile (e.g., mixed layer depth and upper-ocean stratification).

The cooling that occurs directly under a hurricane is thought to be of greatest importance for hurricane-ocean interaction (Cione and Uhlhorn 2003) and is also a difficult aspect of the ocean response to observe in situ. Extreme wind speeds and sea surface conditions underneath a hurricane are major obstacles to accurate measurements; consequently, few usable ocean observations have been obtained in the highest wind speed regions near a storm center. Here, we describe in situ ocean measurements made by the Electromagnetic Autonomous Profiling Explorer (EM-APEX) profiling floats that were air launched in front of category-4 Hurricane Frances (2004) (section 2). These floats, described in section 3, together with other in situ data collected during the Coupled Boundary Layer Air-Sea Transfer (CBLAST)-High field experiment (Black et al. 2007; D'Asaro et al. 2007; Zedler et al. 2009), provide some of the most detailed and complete physical descriptions ever made in the upper ocean directly beneath an intense hurricane. A preliminary look at a portion of these data and their use in inferring a drag coefficient was reported previously (Sanford et al. 2007). This paper expands on that work by describing the observations made at all three floats (section 4), by discussing and analyzing aspects of the momentum balance, wind stress inference, and vertical mixing (section 5) and by presenting surface wave estimations (section 5d). A brief summary and a look ahead to future deployments are in section 6 .

\section{Hurricane Frances}

Frances became a tropical depression during the night of 24-25 August 2004 about $1400 \mathrm{~km}$ west-southwest of the Cape Verde Islands and quickly became a tropical storm on 26 August and a hurricane on 27 August. It continued to intensify, becoming a major category-4 hurricane by the evening of 28 August with maximum sustained winds estimated at $115 \mathrm{kt}$. Frances proceeded on a westerly course as it weakened slightly, but reintensification occurred on 30 August and winds increased to $125 \mathrm{kt}$ (category 4) late on 31 August while the storm was moving west-northwest of Hispaniola (Fig. 1) (see http://www.nhc.noaa.gov/2004frances.shtml).

\section{Methods}

\section{a. The EM-APEX floats}

Webb Research Corp. (WRC) and the University of Washington Applied Physics Laboratory (APL-UW)

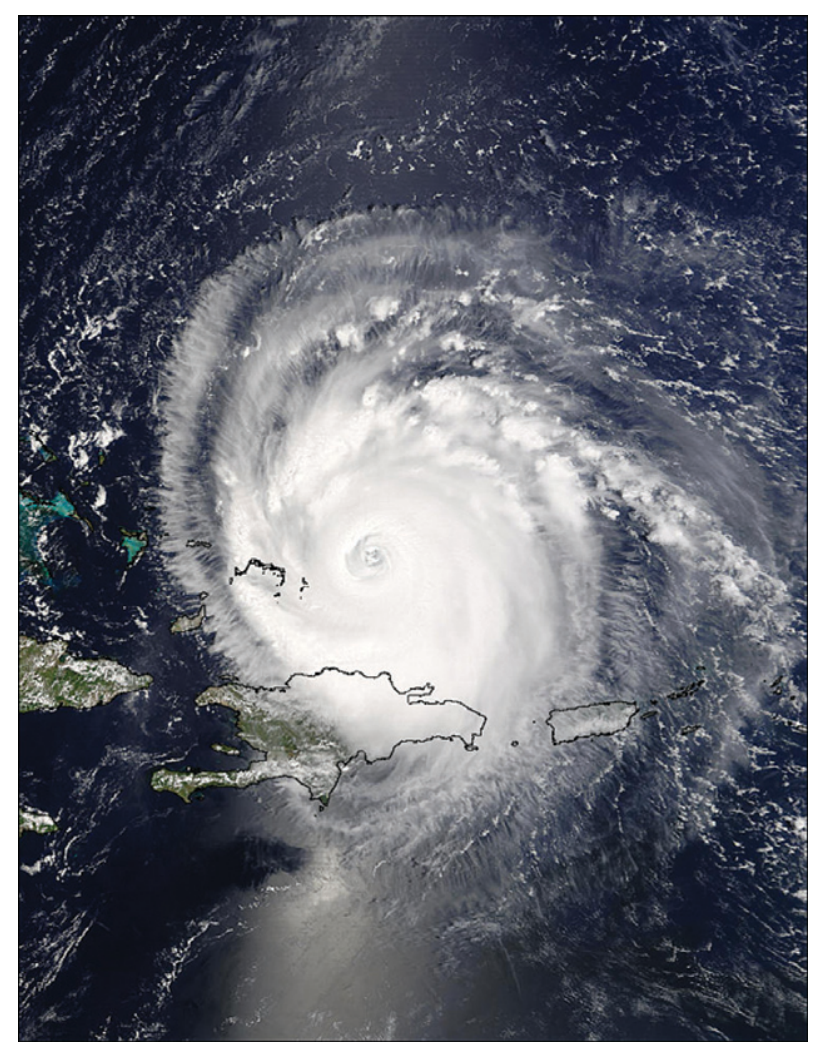

FIG. 1. National Aeronautics and Space Administration (NASA) Terra satellite Moderate Resolution Imaging Spectroradiometer (MODIS) true-color image of Hurricane Frances at 1530 UTC 1 Sep 2004. Frances was located approximately $1200 \mathrm{~km}$ eastsoutheast of southeast Florida, about $250 \mathrm{~km}$ north of Hispaniola. The hurricane was moving toward the west-northwest at $26 \mathrm{~km} \mathrm{~h}^{-1}$ with maximum sustained winds near $220 \mathrm{~km} \mathrm{~h}^{-1}\left(62 \mathrm{~m} \mathrm{~s}^{-1}\right)$. Frances was the seventh costliest Atlantic hurricane during 1900-2004, responsible for 7 direct and 42 indirect deaths and $\$ 8.9$ billion in property damage.

developed the EM-APEX float with support from the Office of Naval Research (ONR) Small Business Innovation Research program. The instrument described by Sanford et al. (2005) is the combination of a standard WRC APEX profiling float with an APL-UW subsystem that measures the motion-induced electric fields generated by the ocean currents moving through the vertical component of the earth's magnetic field. The APEX float changes its buoyancy to enable it to profile the upper $1000 \mathrm{~m}$ of the ocean. Temperature and salinity measurements are obtained from a Sea Bird Electronics SBE41 CTD. When on the sea surface, the float's position is determined by GPS, and the position and accumulated profile data are transmitted over an Iridium global satellite phone system.

The velocity sensor operates on the same principles of motional induction applied on the Absolute Velocity Profiler (Sanford et al. 1985) and the Expendable Current 
Profiler (Sanford 1986). In short, electrodes on a right cylindrical PVC shell surrounding the lower half of the float are used to sense the motional-induced electric field. Other necessary measurements are magnetic compass heading and instrument tilt. The float descends and ascends at $0.10-0.12 \mathrm{~m} \mathrm{~s}^{-1}$ and rotates at a period of $12 \mathrm{~s}$. The motional-induced electric field is determined by a sinusoidal fit to the measured voltages given the known period of float rotation. The fit is made over a 50-s-long segment of data, and the averaging window is moved $25 \mathrm{~s}$ between successive fits. These sinusoidal fits and the rms residuals are transferred to the APEX float controller for storage and later transmission over Iridium. The fits provide an estimate of the horizontal current, and the rms residuals provide an estimate of the velocity noise level. In the upper ocean, the residuals can also be interpreted as a profile of surface gravity wave amplitude (section 6).

Three EM-APEX floats were deployed ahead of Hurricane Frances as part of the ONR CBLAST program. The floats were deployed from a U.S. Air Force (USAF) C-130 operated by the USAF 53rd Weather Reconnaissance Wing. The EM-APEX floats were deployed from 2000 to 2300 UTC 31 August 2004 based on the 0300 UTC 31 August forecast for the 1800 UTC 1 September storm position. The floats where launched on a line perpendicular to the forecasted path of the hurricane about one day ahead of the intense winds (Fig. 2). The forecast proved to be extremely accurate, and float 1636 was placed on the track; float 1633 was deployed about $55 \mathrm{~km}$ to the right (i.e., north of the storm track); and float 1634 was launched $110 \mathrm{~km}$ to the right. Note that only the ocean to the right side of the hurricane track was sampled; the left side of the track was avoided because it was thought to be too close to the windward island arc (about $100 \mathrm{~km}$ to the south of the track).

Three profiling scenarios were specified for the deployment. The first objective was to define the ocean initial condition; hence, the floats profiled from the sea surface to 500-m depth. The second objective was to observe the upper ocean as intensively as possible during the hurricane passage; hence, profiling was performed continuously, giving roughly half-hourly temporal resolution down to 200-m depth. It was expected that the hurricane would generate very strong, three-dimensional turbulence near the sea surface that would be sufficient to overwhelm the rather small buoyancy changes that cause an EMAPEX float to profile. The upper profiling limit was therefore set to $30 \mathrm{~m}$ for a period surrounding the hurricane passage. Even with this precaution, the floats were on some occasions advected vertically at roughly 3 times their nominal profiling rate, $0.1 \mathrm{~m} \mathrm{~s}^{-1}$. No GPS positions were obtained while the floats remained submerged. The

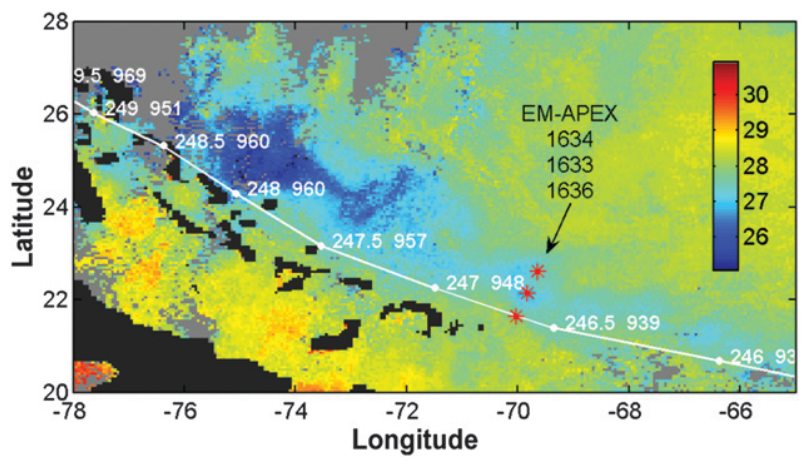

FIG. 2. Sea surface temperature from Geostationary Operational Environmental Satellite (GOES) and the track of Hurricane Frances (2004). The launch positions of three EM-APEX floats deployed about one day ahead of Hurricane Frances are shown as red asterisks. The SST image was acquired about 4 days after Hurricane Frances passed over the EM-APEX floats. The numbers next to the track mark the eye position at half-day intervals (year day, UTC) and the following 3-digit number is the central pressure in millibars.

$T, S, V$, position (if any taken), and engineering data were processed on board for later transmission. Third, about 6 days after deployment, the floats surfaced and transmitted their accumulated data via an Iridium satellite phone link. They then continued profiling from the surface to $500 \mathrm{~m}$ every half inertial period (at $22^{\circ} \mathrm{N}$ an inertial period is $32 \mathrm{~h}$ ) until finally recovered by ship in late September.

EM-APEX floats drift freely with the horizontal current. However, because they move in the vertical, they are not strictly Lagrangian and of course they are not Eulerian either. The horizontal displacements associated with the inertial motions generated by the hurricane are $O(10 \mathrm{~km})$, whereas the horizontal scale over which the response varies significantly is $O(50 \mathrm{~km})$. Hence, for the purpose of this description, we can denote the floats adequately by their deployment locations (i.e., their nominal distance from the hurricane track) Xo $=0,55$, and $110 \mathrm{~km}$ for floats 1636,1633 , and 1634, respectively (as if the resulting measurements were Eulerian).

\section{b. Numerical ocean model}

A three-dimensional (3D) version of the numerical Price-Weller-Pinkel (PWP) (Price et al. 1986) vertical mixing model (3DPWP) developed by Price et al. (1994) and described in part in Sanford et al. (2007) has been used to simulate the ocean response to Hurricane Frances. The hurricane stress field is the most important input to the model; stress was computed from a combination of the HWIND wind field (Powell et al. 1998) for Frances and the high wind speed-saturated drag coefficient of Powell et al. (2003). This $C_{D}$ increases with increasing wind speed up to about $32 \mathrm{~m} \mathrm{~s}^{-1}$ and then decreases for 

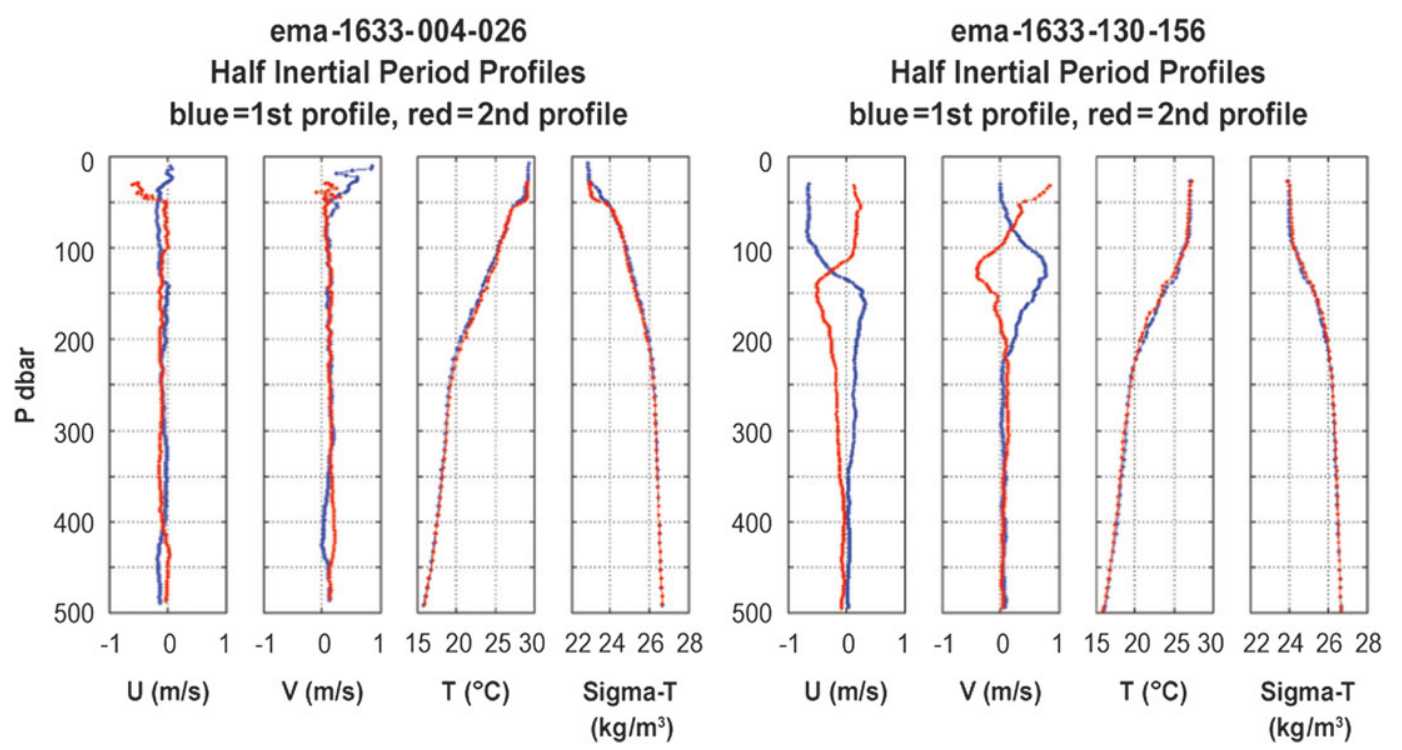

FIG. 3. Profiles of $T, S$, and $V$ (east and north components) observed at intervals of half an inertial period by float 1633 (55 km to the right of the track): (left) observations prior to the cyclone and (right) observations about $2^{1 / 2}$ inertial periods later. The blue lines are data from the first profile (first number in title; e.g., 004) and red is the second profile (e.g., 026). The velocity profiles were computed over $50 \mathrm{~s}$ of raw data, or about 5-6-m depth. Note the clear clockwise rotation of the velocity vector with depth indicating downward group velocity and energy flux.

still greater wind speed until leveling off at $1.5 \times 10^{-3}$ for wind speeds up to about $50 \mathrm{~m} \mathrm{~s}^{-1}$. The resulting stress field has eyewall maximum values of about 5.5 $\mathrm{Pa}$. The amplitude of the simulated ocean response is reasonably good overall compared to the CBLAST observations of SST cooling and maximum current (some aspects described by Sanford et al. 2007). The most notable discrepancy is that the cooling and currents are too large by about $20 \%$ along the track. Reducing the high wind speed value of $C_{D}$ would remedy this. Independent evidence from the EM-APEX-inferred momentum balance also suggests a slightly lower high wind speed value of $C_{D} \sim$ $1.4 \times 10^{-3}$ (again based on the wind velocity from HWIND). Simulations made with this directly inferred $C_{D}$ do not differ significantly from those made with the Powell $C_{D}$. Air-sea heat exchange has been modeled by the usual bulk formulas, assuming constant exchange coefficients, $1.4 \times 10^{-3}$. The (unobserved) dry and wet bulb air temperatures within the hurricane were taken as $26^{\circ}$ and $25^{\circ} \mathrm{C}$, respectively, which are nominal values. The sum of the resulting sensible and latent heat fluxes was estimated to be upward at $1000 \mathrm{~W} \mathrm{~m}^{-2}$ under the leading eyewall. However, this air-sea heat flux is only about $O(0.1)$ of the heat flux into the surface layer caused by vertical mixing (entrainment). Hence, even a significant, several degree change in the air temperature will have little effect on the simulation of SST; hence, we do not discuss this further. Similarly, even a $50 \%$ change in the heat flux exchange coefficients yields only a small difference in the simulated SST; hence, we cannot make a sensitive inference of a possible wind speed dependence of the sensible and latent heat flux exchange coefficients as is possible for the drag coefficient.

To compare the numerical model solution with an EM-APEX float data record, we begin by sampling the model solution along the track of a simulated float that was launched at the appropriate initial position relative to the hurricane track. This virtual float was then advected through the three-dimensional solution by a horizontal velocity that was depth averaged from 30 to $200 \mathrm{~m}$, the EM-APEX sampling range during the period of most interest here. Temperature, salinity, and velocity were sampled in the vertical and saved to make a time-depth section that may be compared to the corresponding EMAPEX record. The differences that result from this EMAPEX-like advection scheme (vs an Eulerian sampling scheme, fixed in space) are noticeable but small compared to the ocean response itself.

\section{Overview of the EM-APEX observations}

The pre-hurricane oceanographic conditions included a strongly stable, shallow thermocline and SST of $29.5^{\circ} \mathrm{C}$ (Fig. 3), which was quasi uniform horizontally based on satellite SST imagery. The initial salinity profile showed a fresher surface layer, about -1 compared to the upper thermocline, which is characteristic of the climatology of this region. The initial surface salinity varied by \pm 0.2 

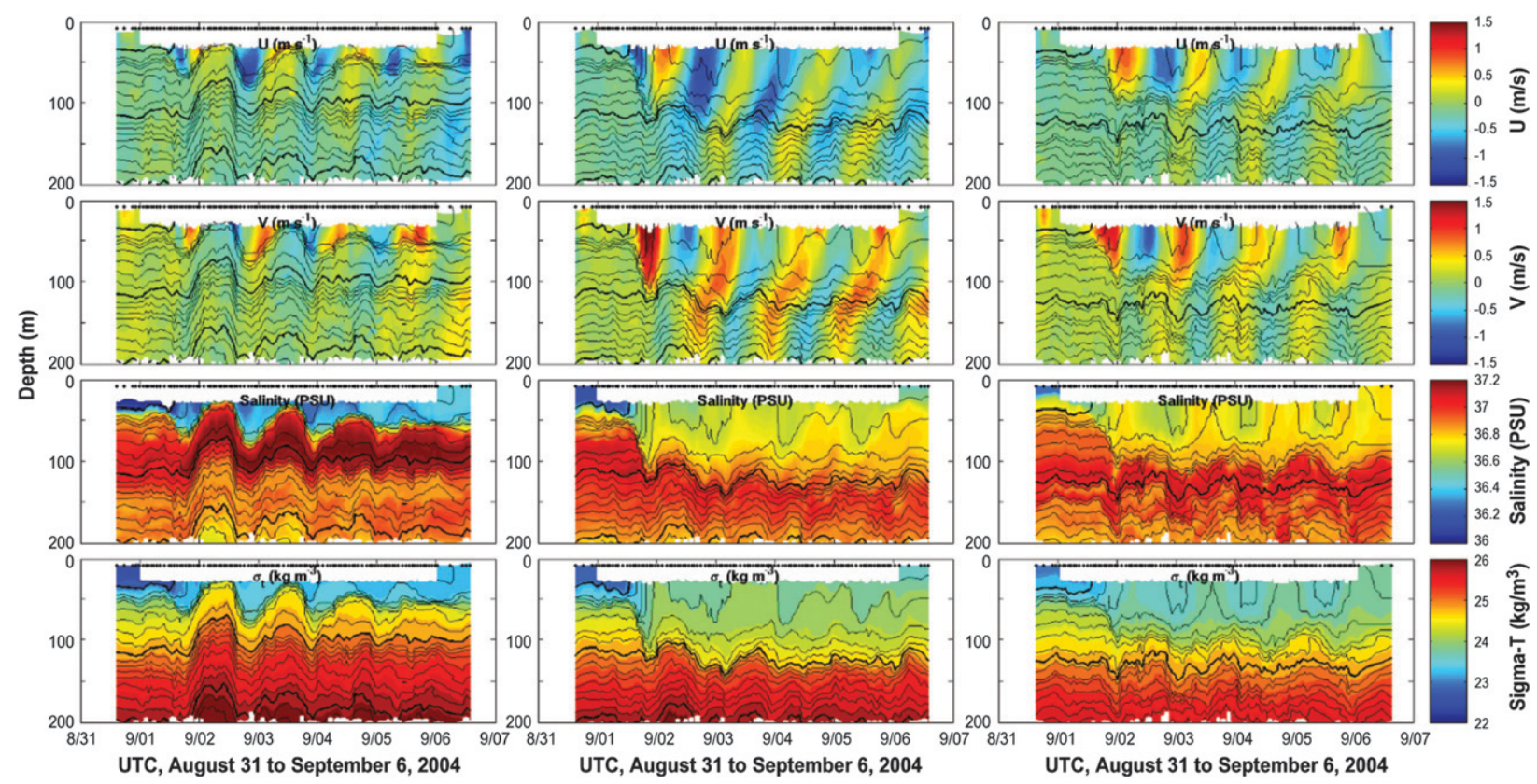

FIG. 4. Contour (colors) plots of (top row) $U$ (east) and (next row) $V$ (north) velocity components ( $\mathrm{m} \mathrm{s}^{-1}$ ) vs depth and time with temperature contours (black lines) for (left to right) 0-, 55-, and 110-km sites. (bottom two rows) Displayed are $S$ and $\sigma_{t}$ (density). The temperature contours are every $0.5^{\circ} \mathrm{C}$ with the $29^{\circ}, 25^{\circ}$, and $21^{\circ} \mathrm{C}$ lines thicker. Only for the first $10 \mathrm{~h}$ and last $14 \mathrm{~h}$ were the EM-APEX floats profiling from the surface to depth; during the hurricane, the floats turned around before reaching the surface. (top) The small dots near the sea surface denote when the up profiles occurred.

over the CBLAST region. The floats were deployed in a large, warm anticyclonic eddy that was flanked by cooler cyclonic features (Black et al. 2007). The thermoclinedepth horizontal currents associated with this eddy were about $0.1 \mathrm{~m} \mathrm{~s}^{-1}$, and the long-term (5 week) displacement of the EM-APEX floats appear to be due mainly to this feature. Experiments with the numerical model that have included similar baroclinic features suggest that this eddy did not have a significant impact on the shortterm (less than one week after the hurricane) ocean response emphasized here (see also Zedler et al. 2009) and is not discussed further.

\section{a. The forced-stage response: $-0.5<t<0.5$ days}

Hurricane Frances arrived at the float positions just after midday (UTC) on 1 September, and peak winds during the afternoon and evening were estimated by HWIND (Powell et al. 1998) at about $55 \mathrm{~m} \mathrm{~s}^{-1}$. Strong winds were present at the EM-APEX float locations for about one day. The strong and time dependent hurricane winds generated a clockwise-rotating near-inertial period current with an amplitude of up to $1.5 \mathrm{~m} \mathrm{~s}^{-1}$ in a surface layer that was approximately $60-100 \mathrm{~m}$ thick, depending on location (Fig. 4). During the hurricane passage and coincident with the generation of this nearinertial current, the ocean surface mixing layer deepened by about $80 \mathrm{~m}$ at $\mathrm{Xo}=55 \mathrm{~km}$, as indicated by the rapid rise of isotherms and isohalines toward the sea surface (Fig. 4). The surface layer (and we presume that this is representative also of sea surface temperature) cooled by up to $2.3^{\circ} \mathrm{C}$ in a spatially dependent fashion and salinity increased by about 0.6 . These changes in surface-layer temperature and salinity are consistent with entrainment of cooler and more saline water from the upper thermocline into the surface layer. Consistent with this inference that vertical mixing dominated the surfacelayer heat budget, there was very little change in ocean heat content (computed from the sea surface to $180-\mathrm{m}$ depth) during the time of the most rapid surface-layer cooling [for detailed evaluations of the heat budget during this event, see D'Asaro et al. (2007) and Huang et al. (2009)].

The observed surface-layer cooling was $2.3^{\circ} \mathrm{C}$ at float $1633, \mathrm{Xo}=55 \mathrm{~km}$ to the right of the track (Fig. 5). Cooling was somewhat less at the other two floats, about $1.3^{\circ}$ and $1.7^{\circ} \mathrm{C}$ at $\mathrm{Xo}=0$ and $110 \mathrm{~km}$, respectively. The response of currents was dominated by near-inertial motions at all three sites and with nearly identical phases; the maximum amplitudes of the currents at the three floats were similar, $1-1.5 \mathrm{~m} \mathrm{~s}^{-1}$. Surface-layer thickness differed significantly at the float sites; about $50 \mathrm{~m}$ nearest the track (float 1636), about $120 \mathrm{~m}$ at $55 \mathrm{~km}$ (float 1633), and about $80 \mathrm{~m}$ at $110 \mathrm{~km}$ (float 1634). 

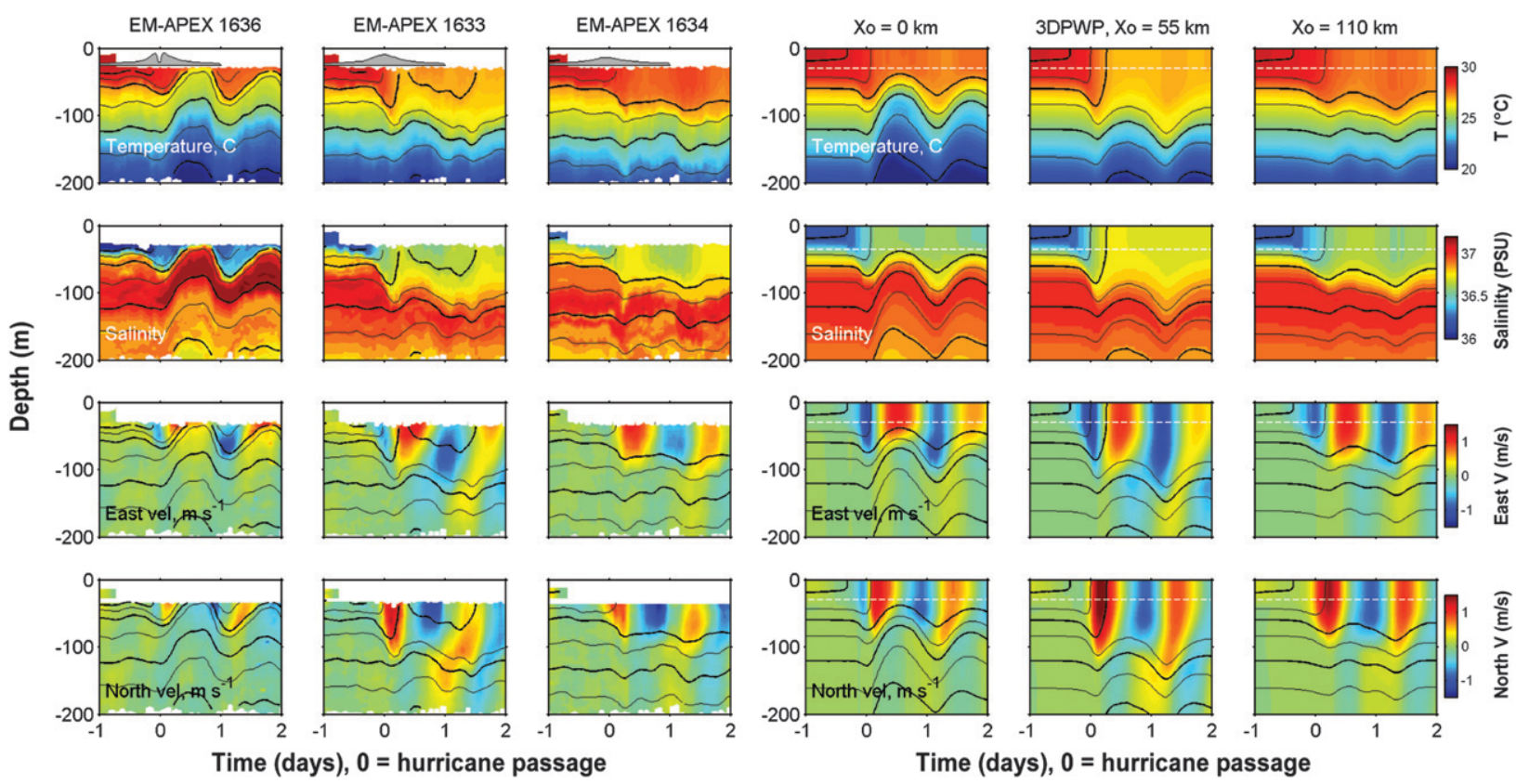

FIG. 5. Time-depth contour plots of (top to bottom) temperature, salinity, and east and north current components (left three columns) as measured by EM-APEX (with float label at the top) and (right three columns) as computed by the 3DPWP ocean model (with corresponding distances from hurricane track at the top). Density is shown as contours at $0.5 \mathrm{~kg} \mathrm{~m}^{-3}$ intervals on each panel. Compared with Fig. 4, this presentation emphasizes the several day period around the hurricane passage. The gray shape just below the surface in the EM-APEX temperature panels is the history of (the square root of) wind stress, showing the time during which the strongest wind stress was present at each of the sites.

\section{b. The relaxation stage response}

The response of temperature and salinity in the upper thermocline included some vertical advection associated with net (time averaged over 3 days after the hurricane) upwelling $\langle\eta\rangle$ as well as significant inertial pumping (upward and downward vertical velocity having a nearinertial period) $\eta^{\prime}$. At Xo $=0 \mathrm{~km}$, the net upwelling was largest, $\langle\eta\rangle \approx 25 \mathrm{~m}$, and the inertial pumping $\eta^{\prime} \approx 25 \mathrm{~m}$. At the site $\mathrm{Xo}_{0}=55 \mathrm{~km},\langle\eta\rangle \approx 25 \mathrm{~m}$, and the inertial pumping $\eta^{\prime} \approx 20 \mathrm{~m}$. At $\mathrm{Xo}=110 \mathrm{~km}$ there was small net downwelling, $\langle\eta\rangle \approx-5 \mathrm{~m}$, and reduced but still appreciable inertial pumping, $\eta^{\prime} \approx 15 \mathrm{~m}$.

A remarkable aspect of the relaxation stage response is the rapid transfer of near-inertial frequency currents from the directly wind-forced surface layer into the upper thermocline. The surface-layer current decayed with an $e$-folding time of about 5 days, and there was a corresponding rise in the amplitude of near-inertial motion in the upper main thermocline. A downward energy transfer also occurred in the upward phase propagation of the upper-thermocline-level current (Fig. 5, bottom two rows). The roughly similar response produced by the numerical model solution indicates that this is a manifestation of a large-scale (resolved in the numerical solution) vertically and horizontally spreading internal wave wake (Price 1983; Zedler et al. 2009).

\section{Energy and momentum balances and an inference of mixing processes}

\section{a. Energy balance}

Energy in a hurricane wake is not, in general, balanced locally (i.e., within a given water column), and it is not balanced within the upper $200 \mathrm{~m}$ of the water column that was sampled intensively by the EM-APEX floats. Energy dispersed rapidly in the vertical below $200 \mathrm{~m}$ and, based on the numerical model solutions, in the horizontal beyond the three positions sampled by EM-APEX. Consequently, from the observations of three floats, we cannot evaluate a closed energy balance in the sense of showing that the observed energy storage is in balance with the source: wind work. A complete energy balance is possible in the model solution, and it is useful to compare the observed and modeled energy variables that are accessible to both datasets (e.g., potential energy and kinetic energy), because they vary markedly from one EM-APEX site to the next. In fact, these energy terms make an objective estimate of the inertial pumping and the currents and energy dispersion described qualitatively in section 4 .

Figure 6 shows the evolution of three energy storage terms and the wind energy input estimated from both the model and observations. The storage terms are the upper layer (0-100 m) kinetic energy, 

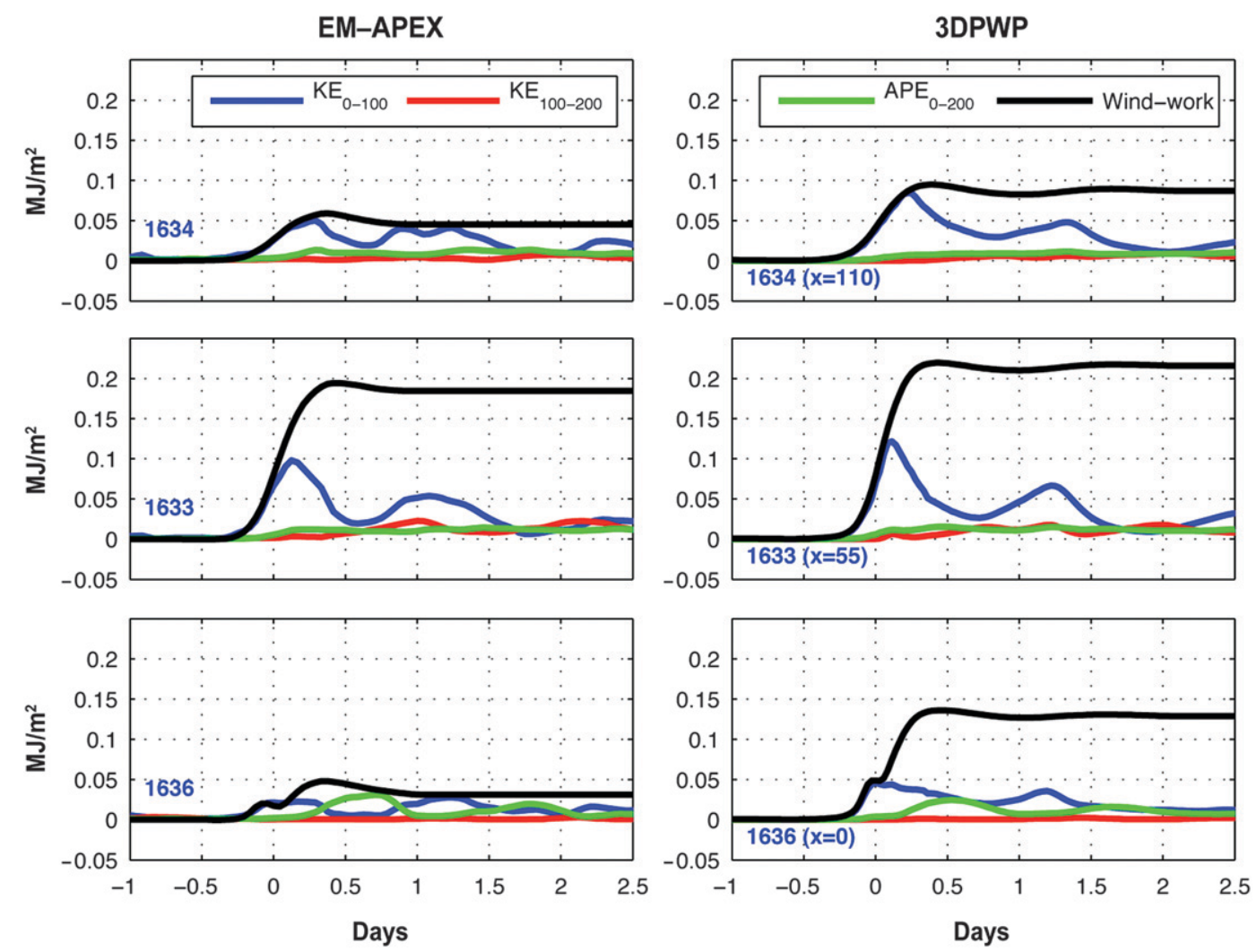

FIG. 6. Energy forcing and storage terms evaluated from (left) EM-APEX float observations (top) $110 \mathrm{~km}$ to the right of the track, (middle) $55 \mathrm{~km}$ to the right, and (bottom) under the eye; and (right) from the numerical model solutions to locations corresponding to deployed floats. The terms are defined by Eqs. (1)-(4); the blue line is upper layer kinetic energy, the red line is upper-thermocline kinetic energy, the green line is available potential energy, and the black line is the time-integrated wind work $[\boldsymbol{\tau} \cdot \mathbf{v}(0)]$ using the HWIND wind fields and the Powell et al. (2003) drag coefficient. Because the intention is to focus on the energetics of the transient response to the storm, the initial velocity has been subtracted from the observed record at float $1636(x=0)$. This avoids a period of negative work prior to the storm's arrival.

$$
\mathrm{KE}_{0-100}=\frac{1}{2} \rho_{0} \int_{-100}^{0}\left(u^{2}+v^{2}\right) d z
$$

the kinetic energy of the upper main thermocline $(100$ $200 \mathrm{~m})$,

$$
\mathrm{KE}_{100-200}=\frac{1}{2} \rho_{0} \int_{-200}^{-100}\left(u^{2}+v^{2}\right) d z
$$

and the one-dimensional available potential energy over the upper $200 \mathrm{~m}$ (Lamb 2008; Holliday and McIntyre 1981),

$$
\mathrm{APE}_{0-200}=g \int_{-200}^{0}\left[\int_{z}^{z^{*}(z)} \rho_{r}\left(z^{\prime}\right)-\rho\left(z^{\prime}\right) d z^{\prime}\right] d z .
$$

The reference density profile $\rho_{r}(z)$ is taken to be the time average of the density profile preceding the hurricane passage, and $z^{*}(z)$ is the height at which the density $\rho(z)$ occurs in the reference profile. This form of the available potential energy is suitable for evaluating changes of the density profile over time due to both mixing and advection, with the caution that mixing will change the reference state $\rho_{r}(z)$. To the extent that the hurricaneinduced mixing is restricted to the neighborhood of the storm track, the initial profile can be thought of as a proxy for the far-field density structure and so remains an appropriate reference state even after the mixing. In the model, this is the case because the initial profile is uniform over the domain. The energy source is the timeintegrated wind work on the surface current,

$$
W=\int_{t_{0}}^{t}\left(\boldsymbol{\tau}_{w} \cdot \mathbf{v}(0) d t\right.
$$

where $t_{0}$ is about one day before the hurricane made its closest approach to the float locations. Wind stress $\tau_{w}$ is estimated using HWIND vectors interpolated to the 
EM-APEX positions and the Powell et al. (2003) drag coefficient; $\mathbf{v}(0)$ is the mixed layer velocity.

EM-APEX floats were programmed to remain below a depth of $30 \mathrm{~m}$ during the hurricane passage and for several days subsequent (section 2). The shallowest measured density and velocity are extrapolated to the sea surface as if there was a density and velocity mixed layer above $z=-30 \mathrm{~m}$. At most times during and after the hurricane passage the shallowest measured density and velocity reveal a vertically homogeneous surface layer and so are consistent with this extrapolation. However, an exception to this occurs along the track at EM-APEX 1636.

In addition to the forcing and storage terms, the model permits the computation of horizontal and vertical energy flux divergence terms, with the result that dissipation by the subgrid-scale mixing scheme can be estimated. The only subgrid-scale process included in the model is vertical mixing associated with shear flow instability. There is no explicit horizontal or vertical viscosity and so, aside from $O(0.1)$ losses due to unintended numerical viscosity, an energy balance may be verified over any spatial domain within the numerical model solution [a simplified example (no vertical mixing) is presented by Price (1983)]. When this is done, the result suggests that $40 \%-50 \%$ of the wind energy input is dissipated locally, which is approximately 5 times the potential energy creation through mixing and roughly consistent with a mixing efficiency of 0.2 (Osborn 1980).

\section{1) QUASI-LOCAL ENERGY BALANCE: $t<0.1$ DAYS}

If the hurricane response were a purely local phenomenon (no advection and hence no pressure gradients), then the energy balance would be between wind work and the storage of surface-layer kinetic energy (less the dissipation associated with vertical mixing) and potential energy increase resulting from mixing effects on the density profile. The observed energy balance at all three locations appears to be nearly local in this sense up until a few hours after the passage of the hurricane eye, $t<0.1$ days; the upper layer kinetic energy closely follows wind work (black and blue curves in Fig. 6). Beyond $t=0.1$ days, this local balance no longer holds. The wind stress remained large at $t=0.1$ days and hence the duration of this quasi-local response does not coincide strictly with the forced-stage response noted in section 4 . That is, the forced-stage response includes appreciable nonlocal effects.

The greatest differences between the modeled and observed energy terms are in the magnitude of the kinetic energy and the total wind work, with both terms weaker in the observations, particularly at EM-APEX 1636 $(\mathrm{Xo}=0)$ and somewhat less so at $1634(\mathrm{Xo}=110 \mathrm{~km})$.
The model-data discrepancy in SST cooling along the track was noted in Sanford et al. (2007) and could arise from one or both of (at least) two sources. 1) The depth of the surface mixed layer along the track was only sporadically below 30-m depth, and hence the extrapolation from the shallowest measured velocity to the surface is likely to give an underestimate of the surfacelayer kinetic energy and, more importantly, the surface velocity used in computing the wind work. 2) The Powell et al. (2003) wind stress used to force the model may still be an overestimate, producing a correspondingly more energetic response. This is supported by the direct evaluation of momentum flux into the surface layer (see section 5 b).

\section{2) NONLOCAL ENERGy BALANCE: $t>0.1$ DAYS}

A quasi-local balance between wind work and surfacelayer kinetic energy lasts for about $2 \mathrm{~h}$ after the eye passage. Beyond that time, energy flux divergence terms in the model (advection and wave propagation; horizontal and vertical) become significant, indicating the onset of nonlocal effects, which are part of the relaxation stage response. The potential energy response remains significantly smaller than kinetic energy, except at EMAPEX 1636 (Xo = 0; Fig. 6, bottom), where there is a large positive increase of potential energy at $t=$ 0.7 days associated with the first maximum of inertial pumping (Figs. 4, 5) and a net positive mean over the week-long period after the hurricane. The potential energy fluctuated in time with a near-inertial period and with an amplitude (half the range) that was comparable to the mean. During an "inertial pumping" cycle, energy appeared to be stored as potential energy during the positive phase and then partially recovered as kinetic energy on the downward-going phase.

The large near-inertial fluctuations of potential energy imply that there are significant (hydrostatic) pressure perturbations associated with inertial pumping and suggest that there could be significant pressure work (i.e., pressure-velocity correlation, such as from inertiagravity wave radiation processes) occurring as well. Consistent with this was a rapid decrease of surface-layer kinetic energy at EM-APEX 1633 and 1634 (Xo = 55 and $110 \mathrm{~km}$, respectively) that may be characterized by an $e$-folding time of about 2.5 days (the current amplitude $e$-folding time is 5 days). There was a smaller rise of upper-thermocline kinetic energy, showing that a portion of the upper-layer kinetic energy was transferred into the upper thermocline. Based on the model solutions, significant fractions of the energy imparted by wind work were dissipated locally, dispersed to greater depths within the thermocline (below $200 \mathrm{~m}$ ), 
or radiated laterally outside the region sampled by the EM-APEX floats.

\section{b. Momentum balance}

The rapidly varying sea state conditions underneath a hurricane are expected to have a significant impact on the drag coefficient and the associated estimate of wind stress. Sanford et al. (2007) found that the modelcomputed momentum change in the upper ocean was less than predicted by traditional wind stress parameterizations (e.g., Large and Pond 1981). Here, a complementary analysis uses the instantaneous EM-APEX velocity measurements to evaluate an upper-oceanintegrated momentum budget over a layer of thickness $H$,

$$
\begin{aligned}
& \int_{-H}^{\eta}\left(\frac{\partial \mathbf{v}}{\partial t}+\mathbf{v} \nabla \cdot \mathbf{v}+\mathbf{v} \cdot \nabla \mathbf{v}+\mathbf{f} \times \mathbf{v}+\frac{1}{\rho_{0}} \nabla p\right) d z \\
& =\frac{\boldsymbol{\tau}_{w}-\boldsymbol{\tau}_{b}}{\rho_{0}}+w_{b} \mathbf{v}_{b},
\end{aligned}
$$

where $\mathbf{v}$ is the horizontal velocity vector $(u, v) \mathbf{f}$ is the vertical Coriolis vector; $\boldsymbol{\tau}_{w}$ is the wind stress; $\boldsymbol{\tau}_{b}$ is the stress at the layer base, parameterized here with an eddy viscosity of $0.001 \mathrm{~m}^{2} \mathrm{~s}^{-1}$, which is large but still not a significant contributor; $\rho_{0}$ is a mean density; $w_{b}$ is the vertical velocity at the base of the layer; $\mathbf{v}_{b}$ is the horizontal velocity at the base of the layer; and $p$ is pressure, determined by vertically integrating the density and assuming no change at $200 \mathrm{~m}$. In evaluating the integral budget here, we assume negligible contribution from the surface elevation $\eta$ (though not necessarily negligible surface pressure) and take $H=150 \mathrm{~m}$ so that the full mixed layer is always included. Three terms are dominant in this balance: the wind stress, the local acceleration, and the Coriolis term. The drag and vertical advection terms at the layer base are nearly always negligible. The terms involving horizontal gradients of $u$, $v$, and $p$, estimated from differences between the float positions or by assuming equivalence between time derivatives and along-track derivatives $\left[\partial u / \partial y=\left(1 / V_{H}\right)(\partial u /\right.$ $\partial t)$ ], where $V_{H}$ is the storm translation speed and $y$ is the along-track direction), are generally quite small during the period before the eye passage $(t \leq 0.2)$. Comparisons between the model's momentum budget using floatsampled gradient terms versus the centered-difference gradients on the model's 5-km grid reveal that, although the float-sampled gradients produce appropriate magnitudes for the terms, the instantaneous errors in the gradient terms are large enough that the momentum budget cannot be closed with the $50-\mathrm{km}$ float sampling. That is, for $t>0.2$, the momentum residual is comparable in

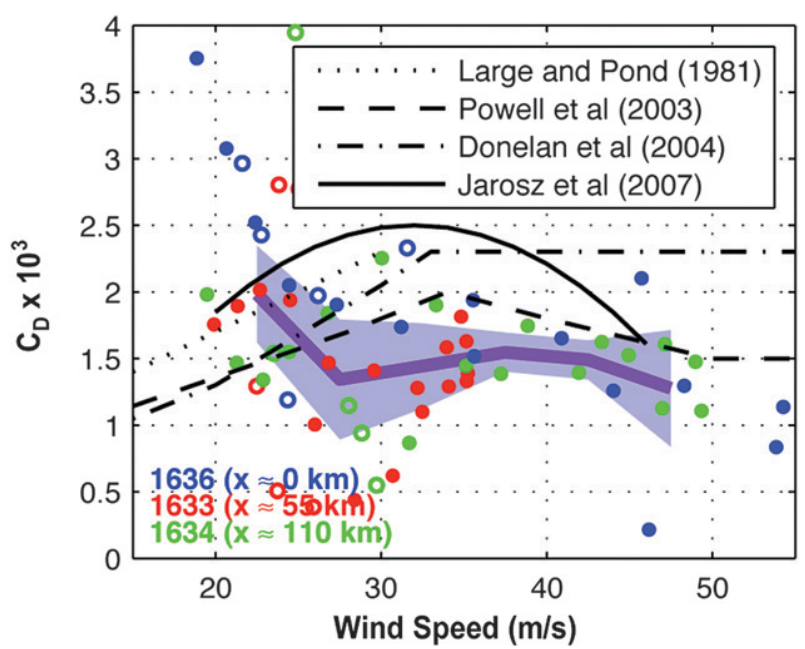

FIG. 7. Estimates of drag coefficient $C_{D}$ based on all profiles during the initial response to Hurricane Frances. The observations before the eye passage (filled circles) are averaged into $5 \mathrm{~m} \mathrm{~s}^{-1}$ bins (dark purple curve) with shading indicating $95 \%$ confidence limits derived from the standard error of the bin averages. Observations after the eye passage (open circles) and below $20 \mathrm{~m} \mathrm{~s}^{-1}$ wind speed are not included in the bin averaging because of the inability to close the upper-ocean momentum budget at these times. Additional curves indicate the $C_{D}$ dependencies described by Large and Pond (1981), Powell et al. (2003), Donelan et al. (2004), and Jarosz et al. (2007).

magnitude to the wind stress. A measurement spacing of $20 \mathrm{~km}$ or finer may be needed to reasonably close the momentum budget over the latter half of the storm passage. By focusing on the mainly local early forced-stage response with significant winds, it is possible to treat the momentum budget as closed, allowing an estimation of the $\tau_{w}$ that satisfies Eq. (5). This approach follows Jarosz et al. (2007), except in some momentum budget details such as bottom drag, which is necessary in shallow water but not here, and entrainment, which is included here but not in the shallow water case. Figure 7 shows the resulting stress estimates, converted to drag coefficients and plotted versus wind speed.

The individual estimates (centered differences over $2 \mathrm{~h}$ ) are noisy, but when bin-averaged over $5 \mathrm{~m} \mathrm{~s}^{-1}$ intervals of wind speed a pattern emerges (dark purple curve in Fig. 7). Previous estimates of drag coefficient under high wind speed indicate a leveling off or even decrease in $C_{D}$ at wind speeds greater than $40 \mathrm{~m} \mathrm{~s}^{-1}$ (Donelan et al. 2004; Powell et al. 2003; Jarosz et al. 2007). Over the range of usable wind speeds sampled here, our estimated drag coefficient shows little variation with wind speed; that includes the range $20-30 \mathrm{~m} \mathrm{~s}^{-1}$, where Powell et al. (2003) and other previous compilations show an increase. The $C_{D}$ estimates made in the very high wind speed range, which are of greatest 
interest, are roughly consistent with the high wind speed values of Powell et al. (2003), $C_{D} \sim 1.4 \times 10^{-3}$. Nearly all previous estimates of $C_{D}$ are a relation between stress in the lower atmosphere and wind speed, whereas here the stress is that in upper-ocean currents. The lower $C_{D}$ of our estimates may be a result of a significant amount of stress entering the surface wave field in this stage of the storm. Model testing by Fan et al. (2009) shows differences of as much as $15 \%$ between the stresses applied by the wind on the ocean surface and the stress accelerating the mixed layer. This difference is largest in the front-right quadrant of the storm, which is where the majority of our estimates were made. The surface gravity waves observed by the floats (section $5 \mathrm{~d}$ ) increased the most during the period over which these stress estimates were made.

Using a constant $C_{D}=1.4 \times 10^{-3}$ to estimate stress in the model simulation, the result is slightly reduced amplitude of currents and sea surface cooling (Fig. 8). The estimate is in agreement with the result presented by Zedler et al. (2009). The phase of ocean currents and inertial pumping is unaffected. The wind speed range from 25 to $35 \mathrm{~m} \mathrm{~s}^{-1}$, where our $C_{D}$ is lower than that of Powell et al. (2003), is not important in these simulations. However, using a $C_{D}$ that increases with wind speed throughout the range of Hurricane Frances wind speeds results in far too much momentum flux into the ocean and too much cooling (Sanford et al. 2007). The greatest sensitivity in the choice (or estimation) of $C_{D}$ is thus in the highest wind speed range $>35 \mathrm{~m} \mathrm{~s}^{-1}$.

\section{c. Surface mixed layer processes and evolution}

Analysis of the surface-layer cooling under H. Francis (D'Asaro et al. 2007; Zedler et al. 2009) shows that significant surface-layer cooling was due mainly to vertical mixing during the roughly 12-h passage of the hurricane. The cooling - and by inference the vertical mixing - was considerably stronger on the right side of the track than on the left. This right-side bias has been attributed to the asymmetric turning of the wind stress vector: clockwise on the right side of the track and so partially resonant with wind-driven inertial motion and anticlockwise on the left side. Stronger surfacelayer velocity produces greater vertical mixing by virtue of vigorous shear flow instability over a deeper surface layer. The combined current and density (temperature and salinity) observations by EM-APEX floats make it possible to examine in some detail the evolution of velocity shear and stratification in relation to the vertical (diapycnal) mixing. The ratio of stratification to shear squared is the gradient Richardson number, as defined in (6),

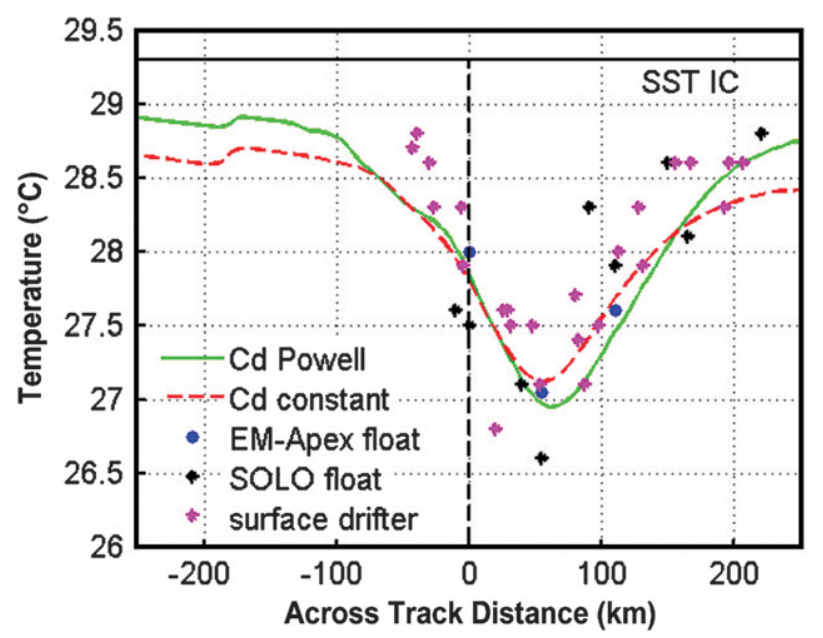

FIG. 8. Across-track profiles of SST cooling due to Hurricane Frances estimated from float observations (discrete points) and from 2 model simulations (green and red lines). The cooling estimated from float data has an uncertainty of $\pm 0.2^{\circ} \mathrm{C}$ and an uncertainty in space (referred to the track) of about $10 \mathrm{~km}$. The model simulations use different drag coefficients to estimate wind stress. The Sounding Oceanographic Lagrangian Observer (SOLO) float data are thanks to Eric Terrill, and drifter data are thanks to Peter Niiler. See D'Asaro et al. (2007) for a comprehensive discussion of these data.

$$
\mathrm{Ri}=\frac{N^{2}}{S^{2}}=\frac{-\frac{g}{\rho_{0}} \frac{\partial \rho}{\partial z}}{\frac{\partial u^{2}}{\partial z}+\frac{\partial v^{2}}{\partial z}}
$$

The density observations are point observations, whereas the velocity values are fits over $50 \mathrm{~s}$, or 5-6 m. A striking observation from these floats is that the gradient Richardson number approached $1 / 4$, the critical value for the onset of stratified shear flow instability, down to depths as great as $120 \mathrm{~m}$ at EM-APEX 1633 $(\mathrm{Xo}=55 \mathrm{~km})$ during the hurricane passage. The value of $\mathrm{Ri}$ approached $1 / 4$ at the other sites as well, though over a smaller range of depths.

In a single profile (at a single time), we can show the profile of the gradient Richardson number (Fig. 9) calculated by taking first differences of density and horizontal (vector) current over $\pm 5 \mathrm{~m}$ and with no smoothing otherwise. Over this 5-m vertical scale, the measured profiles of current, temperature, and salinity appear to be smoothly varying, even where the Richardson number is smallest. We interpret the profiles as the mean (resolved) motion rather than the turbulent motion. No doubt many profiles would show energetic small scale vertical structure associated with turbulent overturning events if sampled on a smaller vertical scale. The red vector at the top of the profile is in the direction of the wind stress (from HWIND analysis). The Richardson number is shown on a log base 4 scale. Red symbols indicate a very 


\section{EM-APEX time $=0.24$ days $\quad$ 3DPWP}
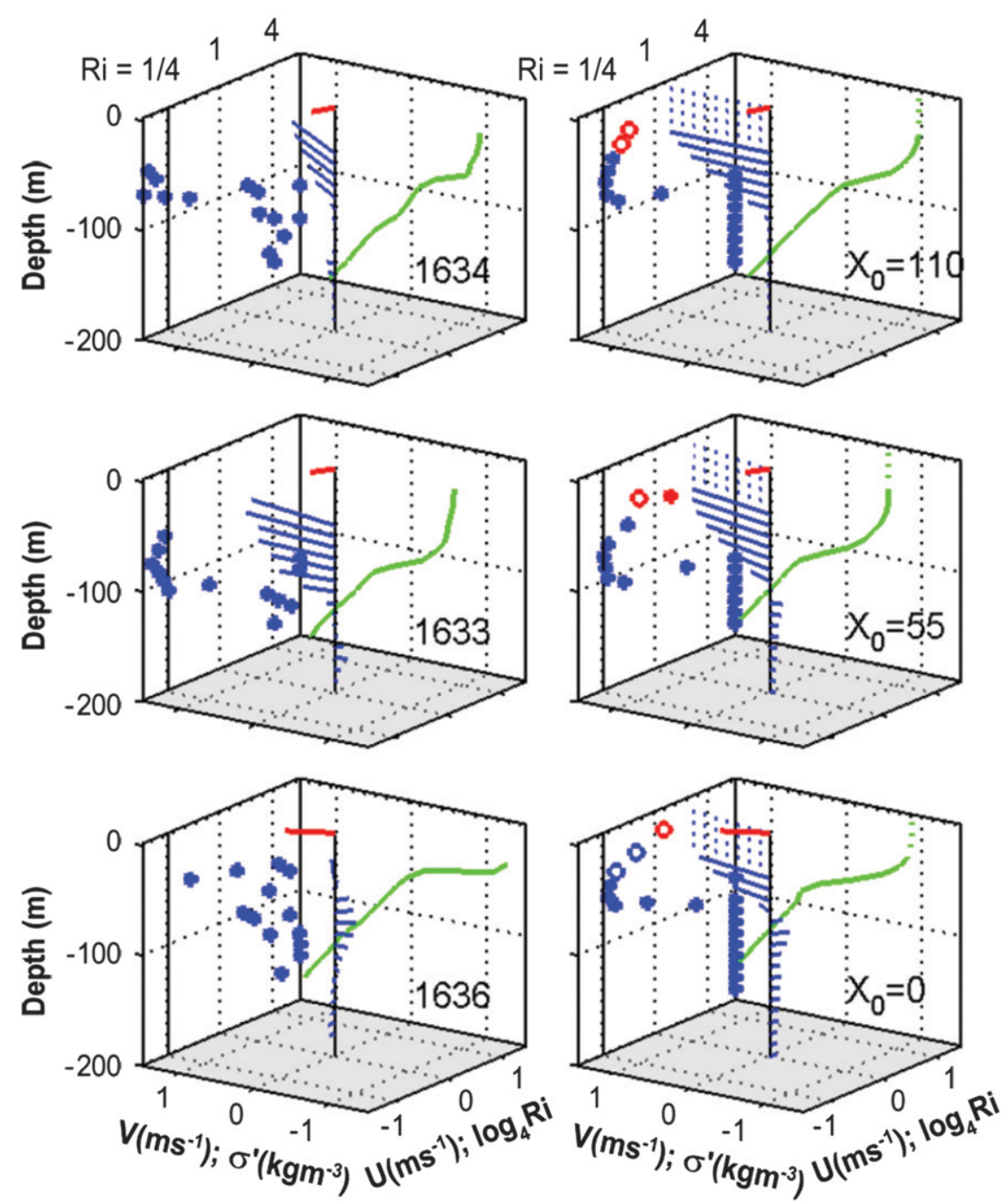

FIG. 9. Snapshots of (left) observed and (right) simulated profiles of horizontal velocity (blue vector sticks) and density (green profiles in the right background). The red vector at the sea surface $z=0$ shows the direction of the wind (taken from HWIND and the same in EM-APEX and model profiles). The dotted current vectors in the model profiles are at the shallow depths not sampled by EM-APEX. The green line in the right background is the density anomaly, $\sigma^{\prime}=$ $\rho-1024.5 \mathrm{~kg} \mathrm{~m}^{-3}$. The numerical scale for $\sigma^{\prime}$ is the same as for the $v$ component of velocity $\left(\mathrm{m} \mathrm{s}^{-1}\right)$. The dots in the left background are estimates of the gradient Richardson number computed by first differences over $10 \mathrm{~m}$. Red dots are estimates made where the density difference was less than $0.002 \mathrm{~kg} \mathrm{~m}^{-3}$ over $10 \mathrm{~m}$ (i.e., in a depth range that was nearly homogeneous). Open dots in the model profiles are at shallow depths not sampled by EM-APEX. (A much more extensive set of these profiles that may be viewed as an animation is available as supplemental material at the Journals Online Web site: http://dx.doi.org/10.1175/2010JPO4313.s1.)

small density gradient (i.e., $0.001 \mathrm{~kg} \mathrm{~m}^{-3}$ over $10 \mathrm{~m}$ ), with the intent being to flag Ri estimates that were made within a density homogeneous mixed layer, because the interpretation of $\mathrm{Ri}$ as a stability limit on stratified shear flow would then be moot. A single snapshot of Ri at time $t=0.24$ days, just after the strongest winds in the rear half of Hurricane Frances had passed the EM-APEX sites, shows the time when the current magnitude was near a maximum (Fig. 9). The current and density profiles observed at the three EM-APEX floats (left column) are shown along with the comparable estimates made from the 3DPWP model solution (right column). An extensive 

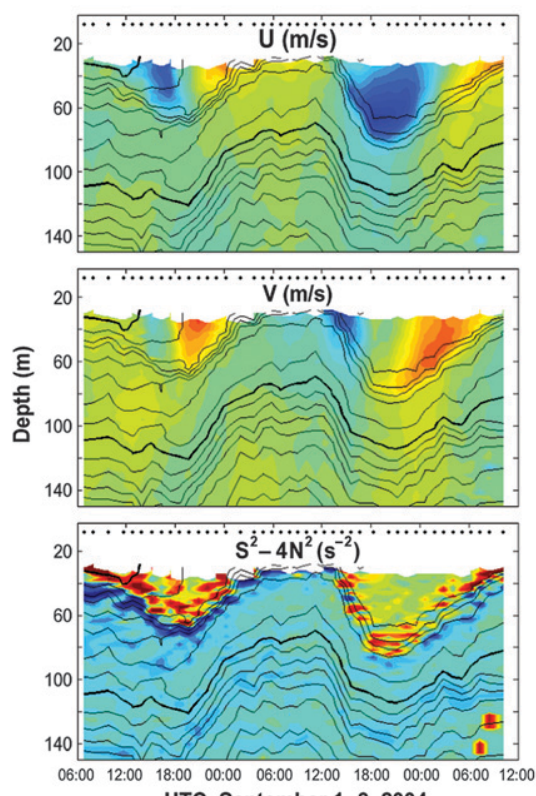

UTC, September 1-3, 2004
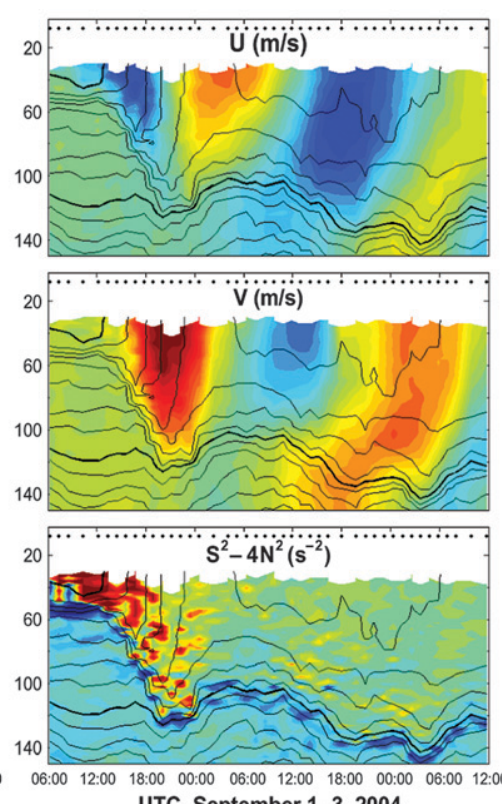

UTC, September 1-3, 2004

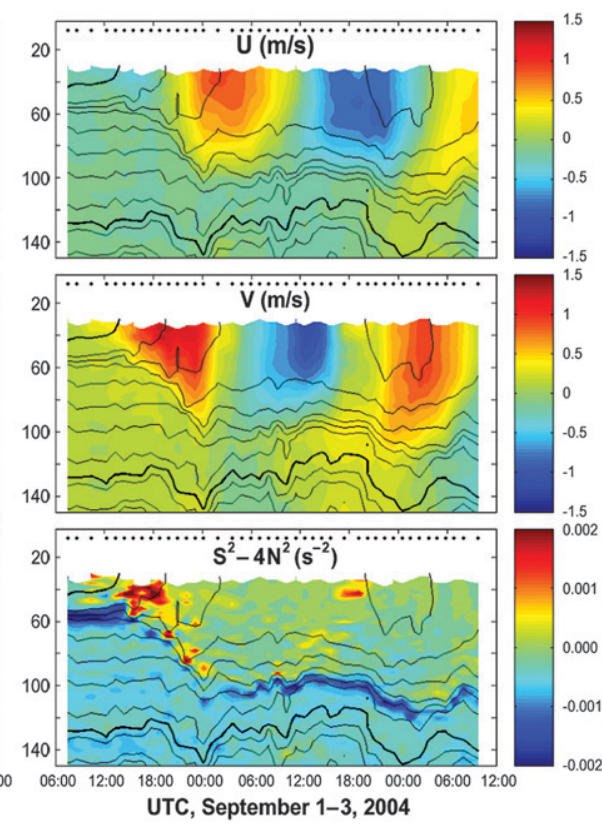

FIG. 10. Upper-ocean responses to Hurricane Frances observed by EM-APEX floats, which were deployed about 1 day ahead of the hurricane passage and (left) under the eye, (center) $55 \mathrm{~km}$ to the right of the track, and (right) $110 \mathrm{~km}$ to the right. Contour plots are depth vs time of $U$ (east) and $V$ (north) current components $\left(\mathrm{m} \mathrm{s}^{-1}\right)$ and reduced shear $S^{2}-4 N^{2}\left(\mathrm{~s}^{-2}\right)$. Isotherms are overlaid, with lines every $0.5^{\circ} \mathrm{C}$; the bold lines are $29^{\circ}$ and $25^{\circ} \mathrm{C}$. The time scale begins at 0600 UTC 1 Sep 2004 . The small diamond symbols denote the time the profiler started rising. Strong vertical shear was observed between 1200 and $21001 \mathrm{Sep}$, with concurrent upper-ocean cooling shown by the rise of isotherms to the surface and the propagation of momentum into the stratified upper ocean.

set of Richardson number profiles at other times around the hurricane passage is available in the supplementary material (http://dx.doi.org/10.1175/2010JPO4313.s1).

The occurrence of a density mixed layer within the surface layer makes it somewhat easier to interpret timedepth sections of the reduced shear $S^{2}-4 N^{2}$ in place of the Richardson number (Fig. 10). The importance of shear relative to stratification is clearer than when presented as the ratio. Note that reduced shear is 0 when $\mathrm{Ri}=1 / 4$. When $S^{2}-4 N^{2}$ is positive, the shear is larger than twice the buoyancy frequency and shear instability is likely. On the other hand, when $S^{2}-4 N^{2}$ is negative, $\mathrm{Ri}<1 / 4$ and shear instability is inhibited.

Although the current amplitude, amplitude of upwelling, and inertial pumping differed considerably at the three float sites, the Richardson number profiles are nevertheless similar in the following respects.

\section{1) BEFORE THE HURRICANE ARRIVAL: $t<-0.5$ DAYS}

Below the initial surface layer (below about $30 \mathrm{~m}$ ), the Richardson number was uniformly large, with values typically greater than 10 . There was strong, stable stratification and little vertical shear of the horizontal current within the upper thermocline, so the pre-hurricane upper thermocline was far from a state of shear flow instability.

\section{2) DURING THE HURRICANE PASSAGE: $-0.5<t$ $<0.5$ DAYS}

Within the strongly sheared transition layer at the base of the surface mixed layer, the gradient Richardson number was close to $1 / 4$. This transition layer was strongly stratified (the density difference was approximately $0.5 \mathrm{~kg} \mathrm{~m}^{-3}$ ) but was also strongly sheared (the velocity difference over this layer was approximately $1 \mathrm{~m} \mathrm{~s}^{-1}$ ). The vertical shear of the wind-driven current was thus sufficient to reduce the gradient Richardson number to values near $1 / 4$ (Figs. 9, 10). The difference between the three sites is mainly in the depth range over which $\mathrm{Ri} \sim 1 / 4$ appeared: 30-60 $\mathrm{m}$ at EM-APEX 1636 at $\mathrm{Xo}=0 \mathrm{~km} ; 60-120 \mathrm{~m}$ at EM-APEX 1633 at $\mathrm{Xo}=$ $55 \mathrm{~km}$; and $50-90 \mathrm{~m}$ at EM-APEX 1634 at $\mathrm{Xo}=$ $110 \mathrm{~km}$. The lowest value of the Richardson number is about the same at all three sites, but the depth range (layer thickness) over which it approaches a (quasi) critical value varies considerably and is greatest where the forcing was strongest.

In the 3DPWP numerical model, $\mathrm{Ri}=1 / 4$ is assumed to be a limit where vertical mixing occurs as fast as required to maintain $\mathrm{Ri} \geq 1 / 4$. Thus, the lowest $\mathrm{Ri}$ values found in the transition layer of the numerical model solution cluster precisely on the line $\mathrm{Ri}=1 / 4$ (the profiles on the right side of Fig. 9). In the EM-APEX data (profiles on 
EM-APEX time $=0.24$ days $\quad 3 D P W P$

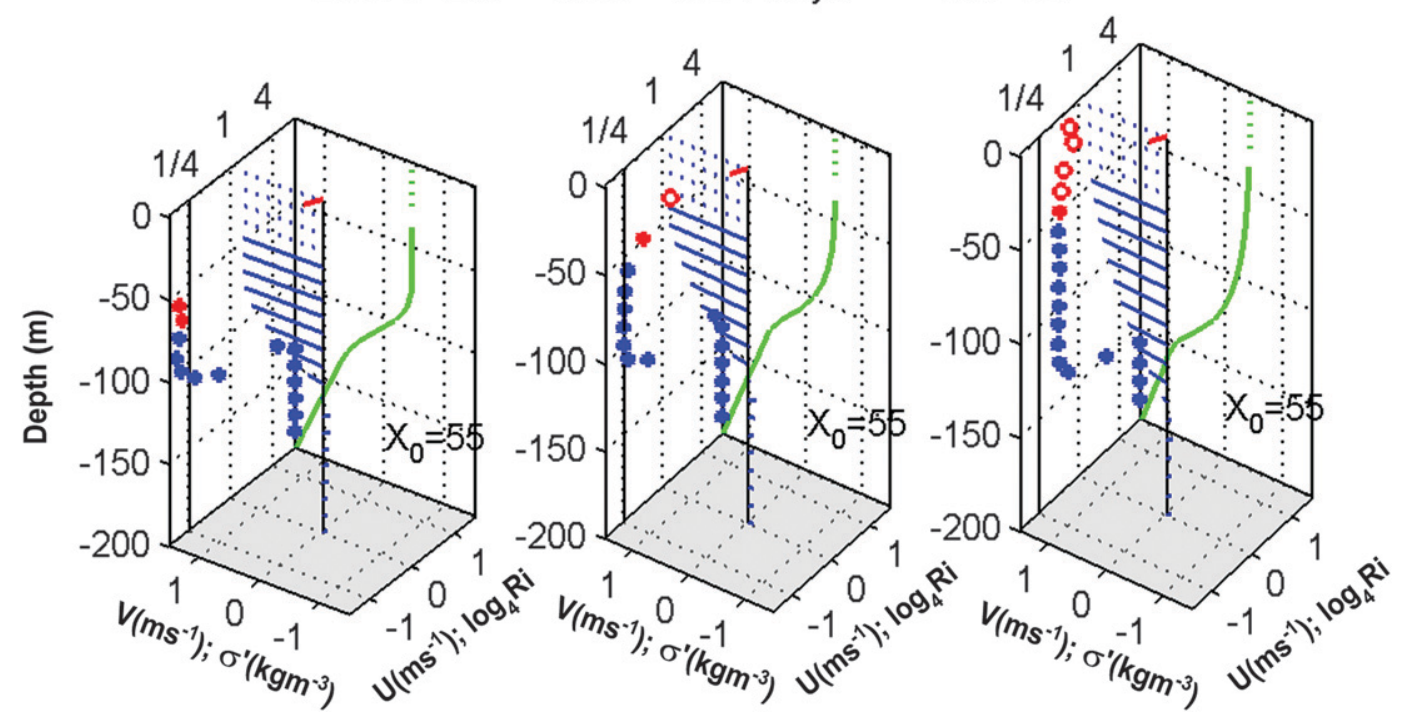

FIG. 11. Profiles of current, density, and Richardson number from 3 numerical experiments as in Fig. 9. The presumed value of the critical gradient Richardson number was (left to right) $1 / 8,1 / 4$, and $1 / 2$. (middle) The data presented is the same as (middle right) in Fig. 9. Note that there is little difference between $1 / 8$ and $1 / 4$ compared to the concurrent observations from EM-APEX 1633 (Fig. 9, middle left) but that the choice of the critical Ri $=1 / 2$ gives too thick a transition layer.

the left side of Fig. 9), there are instances of Ri slightly less than $1 / 4$ but not as low as $1 / 16$ in the stratified portion of the water column. Thus, although $\mathrm{Ri} \geq 1 / 4$ is an exact hard limit in the numerical model solution, it appears to be an approximate lower limit in the field data. Nevertheless, $\mathrm{Ri} \geq 1 / 4$ is a reliable semiquantitative predictor of the maximum shear and density gradient in the stratified part of the water column, even when the shear and the stratification are changing over more than an order of magnitude. We infer that it is not a coincidence that Ri does not fall below $1 / 4$.

To judge the sensitivity of vertical mixing to the presumed value of the critical Richardson number, numerical experiments were run in which the presumed critical value was changed by a factor of 2 (Fig. 11). The lower value of critical Richardson number yields a transition layer that looks only slightly thinner than observed (Fig. 9) and a slightly thicker mixed layer. Using a larger value, $\mathrm{Ri}=1 / 2$, produces a transition layer that is too thick compared with the observations. There is some sensitivity to the critical value of $\mathrm{Ri}=1 / 4$, though we do not claim this as an unexceptional fact.

\section{3) AFter the HuRricANe: $t>0.5$ DAYS}

After the hurricane passage, the winds were comparatively light and the surface-layer currents were almost unforced by the wind. The large-amplitude currents generated during the hurricane passage began to rotate as a near-inertial motion and were decelerated by the process of pressure work on the thermocline (i.e., by dispersion). It is striking that the Richardson number remained close to $1 / 4$ for at least several days after the hurricane passage and after strong vertical mixing had likely ceased. Thus, the Richardson number can remain near $1 / 4$ with little mixing taking place, provided that there is no significant forcing in the direction that would push the Richardson number toward smaller values. If $\mathrm{Ri} \sim 1 / 4$ and the fluid is forced toward still smaller $\mathrm{Ri}$ (e.g., by wind stress in the direction of the velocity shear, by pressure gradients, or by straining), then vertical mixing can be expected; greater forcing produces a thicker layer over which $\mathrm{Ri} \sim 1 / 4$. On the other hand, if the fluid is unforced, then little or no vertical mixing need occur even while Ri is close to $1 / 4$.

\section{d. Surface gravity waves}

The slow rise and fall rate of the EM-APEX float facilitates the separation of velocity into surface wave and low-frequency components (Fig. 12a). Using the exponential decay and dispersion characteristics of linear deep-water waves, it is possible to estimate the significant wave height $H_{s}$ and period $T_{s}$ of the dominant waves from the surface root-mean-square amplitude $u_{\mathrm{rms}}(0)$ and $e$-folding depth $\delta=g / \omega^{2}$ of the wave velocity (i.e., the residual of the electric field demodulation) according to the relations 

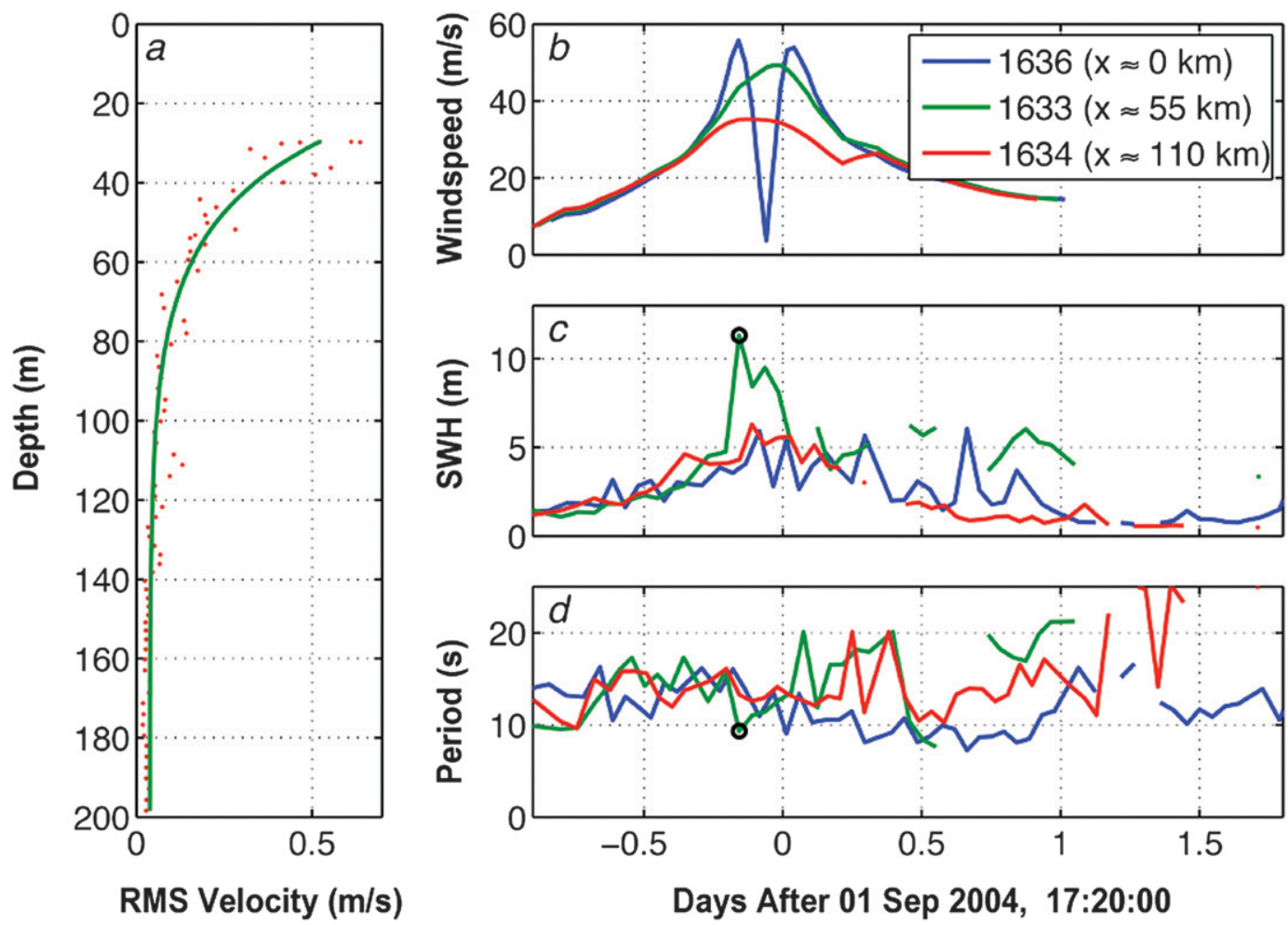

FIG. 12. Surface-wave characteristics measured by the EM-APEX floats. (a) A single profile of the high-frequency velocity amplitude (50-s rms values from float 1633 during the wave peak about $2 \mathrm{~h}$ before the eye passage) shows the exponential decay characteristic of surface gravity waves $\left[u_{\mathrm{rms}}(0)=1.9 \mathrm{~m} \mathrm{~s}^{-1}\right.$ and $\left.\delta=22 \mathrm{~m}\right]$. (b)-(d) Time series of wind speed, significant wave height, and surface wave period estimated from the velocity amplitude $u_{\mathrm{rms}}$ and $e$-folding depth $\delta$ for each EM-APEX.

$$
H_{s}=4(\delta / g)^{1 / 2} u_{\mathrm{rms}}(0) \text { and } T_{s}=2 \pi(\delta / g)^{1 / 2},
$$

where $g$ is the acceleration of gravity. Time series of wave properties at the three floats (Figs. 12c,d) illustrate the buildup of large waves in advance of the storm's center and subsequent decay in the confused seas following the eye passage. The wave period evolution is noisy, depending only on the decay scale (less well constrained by the exponential fitting). Nevertheless, there is a suggestion of an increase in period due to the arrival of faster-moving swell in advance of the storm. Group speed is linearly proportional to wave period, with the $6 \mathrm{~m} \mathrm{~s}^{-1}$ translation speed of the hurricane corresponding to waves of about 8 -s period.

\section{Summary and conclusions}

The EM-APEX floats air launched ahead of Hurricane Frances (2004) provide the most comprehensive density and velocity observations of the initial conditions, hurricane response, and ocean relaxation following an intense open-ocean hurricane. Air launch permitted deployments ahead of the tropical cyclone at precise locations relative to the predicted storm track. GPS and Iridium capabilities permitted determination of profileaveraged velocity (used to adjust the relative EM velocity to absolute velocity), real-time data transmission, mission changes, and accurate location for float recovery. Velocity observations based on the principles of motional induction returned good results and are in good agreement with numerical model results and computations of Richardson number that illustrate our understanding of how the surface mixed layer deepens. The SBE-41 CTD provided high-quality temperature and salinity observations versus pressure. Together, the density and velocity observations provide clear visualizations of the ocean response in time and space. These floats show that the velocity and SST respond in a closely coupled way; the three-dimensional velocity advects the thermal field, horizontally and vertically, and also causes vertical mixing by way of shear flow instability.

The CBLAST field data presented here have excellent resolution to the right side of the hurricane track, but there are no observations on the left side of the track. This was a consequence of the small number of prototype instruments available at the time of the CBLAST 
(2004) project and of the particular path of Hurricane Frances only about $100 \mathrm{~km}$ north of the Antilles. It would be very worthwhile to make similar measurements on the left side of the track, where wind stress is almost as great as on the right but where currents are expected to be considerably less because of the counterclockwise and thus unfavorable (for inertial motions) rotation of the wind stress vector with time. Thus, the wind stress on the left side of the track is very large by any standard, and yet the currents are expected to be small by comparison with the right side of the track. This must have a substantial impact on vertical mixing but remains to be observed.

The EM-APEX measured currents allow an estimate of the wind stress absorbed by ocean currents. Given also the HWIND wind analysis, we can make a fairly direct (although noisy) estimate of the drag coefficient. The most important high wind speed estimates (wind speeds in excess of $35 \mathrm{~m} \mathrm{~s}^{-1}$ ) indicate that $C_{D}$ is approximately $1.4 \times 10^{-3}$. This is consistent with the Powell et al. (2003) estimates in the high wind speed range. Our estimates are, however, somewhat lower than those of Powell et al. (2003) in the middle range of $25-35 \mathrm{~m} \mathrm{~s}^{-1}$. Most of our estimates come from the front-right quadrant of the hurricane, where wind waves were clearly growing with time and likely exporting momentum outward from the region sampled. It may be that our lower estimates of $C_{D}$ reflect the difference between stress in the lower atmosphere and stress in the upper ocean (i.e., divergent wave momentum flux.) Even with the possibility of wave effects, it is difficult to reconcile our comparatively low estimates of $C_{D}$ with those of Donelan et al. (2004) and Jarosz et al. (2007). We caution, however, that these three floats provide only a small (and incomplete) sample of the hurricane-driven current field, so we regard the present results as suggestive and intriguing but not definitive. It is hoped that future deployments will contribute a significantly greater database for this kind of analysis.

Even at depth, the floats observed the amplitude and period of the dominant surface gravity waves. In the future, a firmware modification will be implemented to determine wave direction. Also, it should be possible to construct a crude directional spectrum using the fact that as the float rises it observes more of the wave spectrum. It is anticipated that more complete surface-wave information could provide valuable insight into the role of surface waves in setting the drag coefficient.

Acknowledgments. The Office of Naval Research supported the development of the EM-APEX float system through SBIR Contract N00014-03-C-0242 to Webb Research Corporation and with a subcontract to APL-UW. J. Carlson and J. Dunlap designed and built the EM subsystem with help from A. Bartlett, M. Ohmart, D. Swift, and C. Craig and with major contributions from Webb Research Corp. We thank P. Black, who coordinated the float deployments with the skilled assistance of the Hurricane Hunters of the 53rd Weather Reconnaissance Squadron of the U.S. Air Force Reserve, and the Hurricane Research Division of NOAA/ AOML for their valuable HWIND analysis. T. Sanford and J. Girton were supported by the Office of Naval Research through Grants N00014-04-1-0691 and N0001407-1-024, and J. Price was supported through Grant N00014-04-1-0109.

\section{REFERENCES}

Black, P. G., and Coauthors, 2007: Air-sea exchange in hurricanes: Synthesis of observations from the Coupled Boundary Layer Air-Sea Transfer Experiment. Bull. Amer. Meteor. Soc., 88, 357-374.

Cione, J. J., and E. W. Uhlhorn, 2003: Sea surface temperature variability in hurricanes: Implications with respect to intensity change. Mon. Wea. Rev., 131, 1783-1796.

D'Asaro, E. A., T. B. Sanford, P. P. Niiler, and E. J. Terrill, 2007: Cold wake of Hurricane Frances. Geophys. Res. Lett., 34, L15609, doi:10.1029/2007GL030160.

Donelan, M. A., B. K. Haus, N. Reul, W. J. Plant, M. Stiassne, H. C. Graber, O. B. Brown, and E. S. Saltzman, 2004: On the limiting aerodynamic roughness of the ocean in very strong winds. Geophys. Res. Lett., 31, L18306, doi:10.1029/ 2004GL019460.

Emanuel, K. A., 1999: Thermodynamic control of hurricane intensity. Nature, 401, 665-669.

Fan, Y., I. Ginis, and T. Hara, 2009: The effect of wind-wavecurrent interaction on air-sea momentum fluxes and ocean response in tropical cyclones. J. Phys. Oceanogr., 39, 10191034.

Holliday, D., and M. E. McIntyre, 1981: On potential energy density in an incompressible stratified fluid. J. Fluid Mech., 107, 221-225.

Huang, P., T. B. Sanford, and J. Imberger, 2009: Heat and energy budgets for surface layer cooling induced by the passage of Hurricane Frances (2004). J. Geophys. Res., 114, C12023, doi:10.1029/2009JC005603.

Jarosz, E., D. A. Mitchell, D. W. Wang, and W. J. Teague, 2007: Bottom-up determination of air-sea momentum exchange under a major tropical cyclone. Science, 315, 1707-1709.

Lamb, K., 2008: On the calculation of the available potential energy of an isolated perturbation in a density-stratified fluid. J. Fluid Mech., 597, 415-427.

Large, W. G., and S. Pond, 1981: Open ocean momentum flux measurements in moderate to strong winds. J. Phys. Oceanogr., 11, 324-336.

Osborn, T. R., 1980: Estimates of the local rate of vertical diffusion from dissipation measurements. J. Phys. Oceanogr., 10, 83-89.

Powell, M. D., S. H. Houston, L. R. Amat, and N. Morriseau-Leroy, 1998: The HRD real-time hurricane wind analysis system. J. Wind Eng. Ind. Aerodyn., 77-78, 53-64.

, P. J. Vickery, and T. A. Reinhold, 2003: Reduced drag coefficient for high wind speeds in tropical cyclones. Nature, $\mathbf{4 2 2}$, 279-283. 
Price, J. F., 1981: Upper ocean response to a hurricane. J. Phys. Oceanogr., 11, 153-175.

1983: Internal wave wake of a moving storm. Part I: Scales, energy budget and observations. J. Phys. Oceanogr., 13, 949-965.

— R. A. Weller, and R. Pinkel, 1986: Diurnal cycling: Observations and models of the upper ocean response to diurnal heating, cooling, and wind mixing. J. Geophys. Res., 91, 8411-8427.

— sponse to a moving hurricane. J. Phys. Oceanogr., 24, 233-260.

Sanford, T. B., 1986: Recent improvements in ocean current measurement from motional electric fields and currents. Proc. Third Working Conf. on Current Measurement, Airlie, VA, IEEE, 65-76.

, R. G. Drever, and J. H. Dunlap, 1985: An acoustic Doppler and electromagnetic velocity profiler. J. Atmos. Oceanic Technol., 2, 110-124.

, J. H. Dunlap, J. A. Carlson, D. C. Webb, and J. B. Girton, 2005: Autonomous velocity and density profiler: EM-APEX.
Proc. Eighth Working Conf. on Current Measurement Technology, Southampton, United Kingdom, IEEE/OES, 152-156.

— J. F. Price, J. B. Girton, and D. C. Webb, 2007: Highly resolved observations and simulations of the ocean response to a hurricane. Geophys. Res. Lett., 34, L13604, doi:10.1029/ 2007 GL029679.

Zedler, S. E., T. D. Dickey, S. C. Doney, J. F. Price, X. Yu, and G. L. Mellor, 2002: Analyses and simulations of the upper ocean's response to Hurricane Felix at the Bermuda Testbed Mooring site: 13-23 August 1995. J. Geophys. Res., 107, 3232, doi:10.1029/2001JC000969.

— , P. P. Niiler, D. Stammer, E. Terrill, and J. Morzel, 2009: Ocean's response to Hurricane Frances and its implications for drag coefficient parameterization at high wind speeds. J. Geophys. Res., 114, C04016, doi:10.1029/ 2008JC005205. 